\title{
Focal depth estimates of earthquakes in the Himalayan-Tibetan region from teleseismic waveform modeling*
}

\author{
Ling Bai ${ }^{1,2, *} \quad$ Jeroen Ritsema ${ }^{2}$ and Junmeng Zhao ${ }^{1}$ \\ ${ }^{1}$ Key Laboratory of Continental Collision and Plateau Uplift, Institute of Tibetan Plateau Research, \\ Chinese Academy of Sciences, Beijing 100101, China \\ 2 Department of Earth and Environmental Sciences, University of Michigan, Ann Arbor MI 48109, USA
}

\begin{abstract}
We estimate the focal depths and fault plane solutions of 46 moderate earthquakes in the HimalayanTibetan region by modeling the broadband waveforms of teleseismic $\mathrm{P}$ waves. The depths of 38 of these earthquakes range between $0-40 \mathrm{~km}$, with a peak at $\sim 5 \mathrm{~km}$. One earthquake is located within the lower crust of the Indian shield. The remaining eight earthquakes occurred between depths of $80-120 \mathrm{~km}$ and are all located in the Pamir-Hindu Kush and the Indo-Myanmar deep seismic zones. None of the earthquakes outside these deep seismic zones are located in the mantle. Global centroid moment tensor (CMT) solutions indicate that most earthquakes in northern Tibet and northern India had thrust-faulting mechanisms and that normal and strike-slip faulting earthquakes occurred primarily in central Tibet. These mechanisms are consistent with the predominantly NNW-SSE compression in the direction of current Himalayan-Tibetan continental collision.
\end{abstract}

Key words: continental collision zone; Tibetan plateau; focal depth; strength of the continental lithosphere

CLC number: P315.3 Document code: A

\section{Introduction}

Due to the collision between the Indian and Eurasian plates since 50-70 Ma, the Tibetan plateau is the highest and widest plateau on the Earth with elevations that exceed $6 \mathrm{~km}$ over an area of $3500 \times 1$ $500 \mathrm{~km}^{2}$ (Figure 1). From north to south, the Tibetan crust is tectonically divided into the Kunlun, SongpanGarze, Qiangtang, and Lhasa terranes (Yin and Harrison, 2000) that are separated by long WNW-ESE trending faults (Deng et al., 2003). Over a $2000 \mathrm{~km}$ wide region, the crust has been thickened up to $85 \mathrm{~km}$ due to N-S shortening in the Tertiary (e.g., Tapponnier et al., 2001), which may have occurred prior to the India-Asia continental collision (Kapp et al., 2005).

Several highly-debated models that explain the

\footnotetext{
* Received 18 February 2012; accepted in revised form 20 June 2012; published 10 December 2012.

+ Corresponding author. e-mail: bailing@itpcas.ac.cn

(c) The Seismological Society of China, Institute of Geophysics,

China Earthquake Administration, and Springer-Verlag Berlin Heidelberg 2012
}

high elevation and crustal uplift of the Tibetan plateau have been proposed, such as the continental extrusion (Tapponnier et al., 2001), lower crustal flow (Royden et al., 1997; Ozacar and Zandt, 2004) and lithosphere delamination (Chen and Tseng, 2007). These geologic processes likely cause strong horizontal heterogeneity and vertical stratification of the continental lithosphere. Compared to the oceanic lithosphere that deforms primarily rigidly, the continental lithosphere often deforms in a more complex manner because of its high temperature (McKenzie et al., 2005), melt-depleted composition (Lee et al., 2011), and positive buoyancy (Cloos, 1993). In oceanic regions, the mechanical strength of the lithosphere increases with depth due to increasing pressure above the brittle-ductile deformation transition; below which a sharp decrease in strength occurs (e.g., Kohlstedt et al., 1995). In contrast, lateral variations in continental lithospheric composition and structure may generate strong spatial variations in strength (e.g. Lowry and Smith, 1995). In general, the nature of strength transition and the mechanical strength of the continental lithosphere remains controversial (Kohlst- 
edt et al., 1995; Jackson, 2002; Burov and Watts, 2006; Bürgmann and Dressen, 2008; Thatcher and Pollitz, 2008). This controversy primarily results from the uncertain strength profile of continental lithosphere and whether the strength of the lower crust is weak with respect to the overlying crust and uppermost mantle lithosphere.

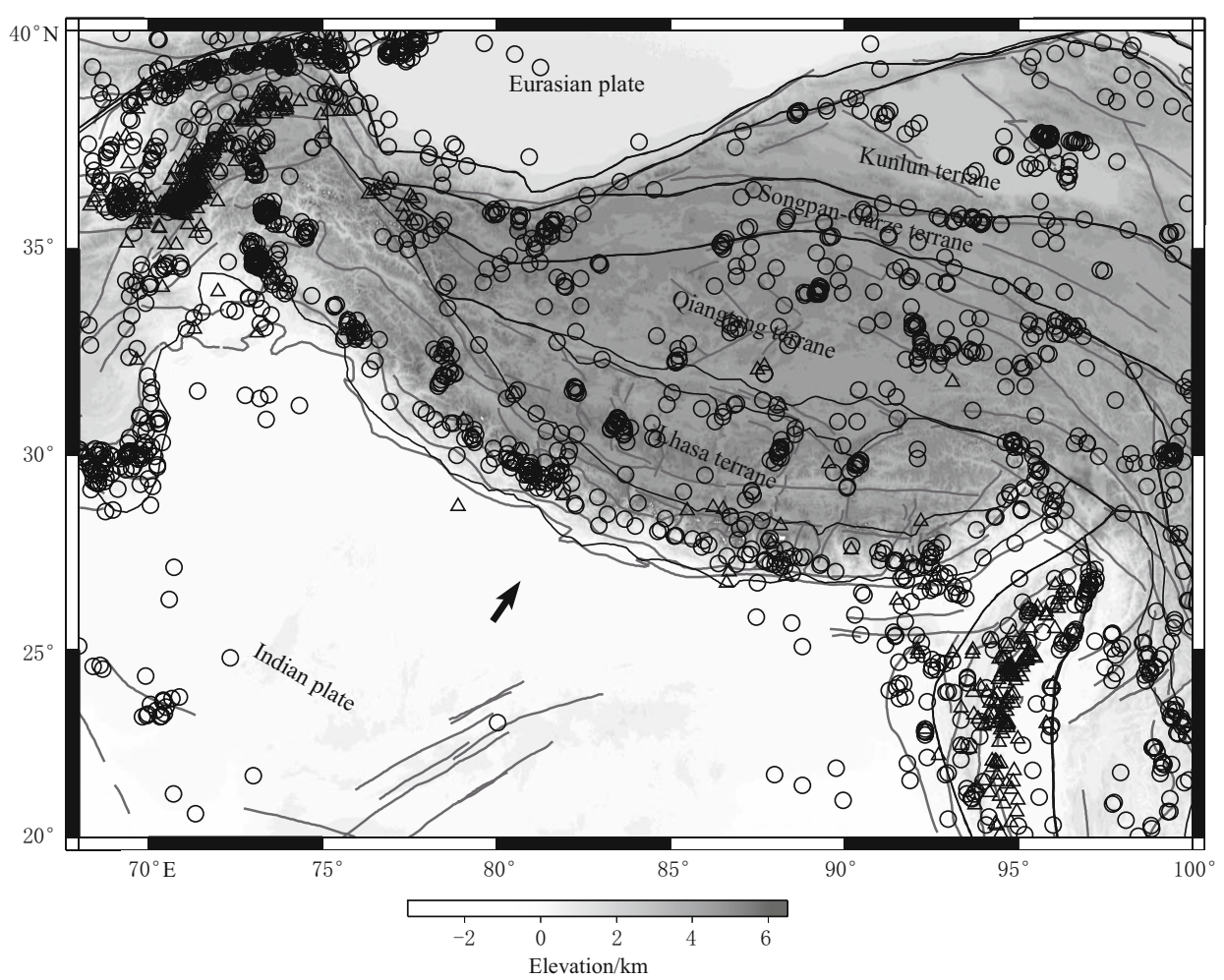

Figure 1 Digital elevation map of the study region showing active faults and the epicentral locations of earthquakes that occurred in the past fifty years. Circles and triangles illustrate earthquakes with focal depth ranging between $0-50 \mathrm{~km}$ and $50-150 \mathrm{~km}$, respectively. There are two zones with earthquakes deeper than 30 km: the Pamir-Hindu Kush and the Indo-Myanmar at the upper left and lower right corners of the study region, respectively. The thick arrow (calculated at the website http://www.unavco.org) shows the absolute plate motion of the Indian plate with respect to the Eurasian plate at a total convergence rate of about $38 \mathrm{~mm} \cdot \mathrm{a}^{-1}$ (Wang et al., 2001). The earthquakes are taken from the USGS PDE catalog.

Chen and Molnar (1983) proposed that the lithosphere beneath the Himalayan-Tibetan region has variable depth-dependent strength profiles, where the overlying crust and the uppermost mantle are much stronger than the intervening lower crust (i.e., jelly sandwich model). This is supported by seismicity, which has a bimodal distribution with maxima in the upper crust and the uppermost mantle (Zhu and Helmberger, 1996; Chen and Yang, 2004; Schulte-Pelkum et al., 2005; Monsalve et al., 2006; Liang et al., 2008; Jiang et al., 2009). Laboratory experiments show that ultramafic mantle rocks are stronger than crustal rocks under similar pressure and temperature conditions (Brace and Kohlstedt, 1980). In the jelly sandwich model, the upper mantle is the strongest part of the lithosphere and thus the long-term strength of the lithosphere is primarily controlled by the upper mantle. However, a number of recent studies (Maggi et al., 2000a, b; Jackson, 2002; Mitra et al., 2005; Priestley et al., 2008) suggest that earthquake focal depths in the Himalayan-Tibetan region strictly reside in a single seismogenic layer, which is slightly thicker than the effective elastic thickness. If earthquakes are restricted to a seismogenic crustal layer, one may infer that the mantle lithosphere is weak and that the strength of the continental lithosphere is governed by the thickness of the crustal seismogenic layer. From these contrasting studies it is clear that the location of earthquake focal depths has strong implications for understanding the strength of the continental lithosphere. 
A seismogenic zone must be sufficiently strong to allow for the build-up of elastic strain. Several analyses of local seismic networks indicate that microearthquakes $(M<5.0)$ beneath the front of the Himalayan arc extend to depth of $\sim 100 \mathrm{~km}$ (Monsalve et al., 2006; Liang et al., 2008; Jiang et al., 2009). Approximately ten percent of these earthquakes occur in the lower crust or the uppermost mantle (Schulte-Pelkum et al., 2005). Focal mechanisms from earthquakes in the mantle indicate strike-slip displacements, whereas the shallow events in the Himalayan region indicate thrust displacements (Zhu and Helmberger, 1996).

Chen and Yang (2004) reported that several moderate earthquakes $(5.0<M<6.0)$ between 1963 and 1999 also occurred in the mantle beneath the Himalayan foreland. Re-examination of these earthquakes (Maggi et al., 2000a, b; Jackson, 2002; Mitra et al., 2005; Priestley et al., 2008), however, suggests that rare earthquakes in the uppermost mantle are mislocated. These authors determine earthquake depths using velocity structures consistent with receiver functions and surface-wave dispersion studies based on several recent passive and active source seismic data. Priestley et al. (2008) also calculated a geotherm for the Indian shield in order to study the temperature dependence of the deformation mechanism and found no evidence for moderate earthquakes in the continental mantle. Jackson (2002) and Priestley et al. (2008) concluded that the earthquakes in the uppermost mantle identified by Chen and Yang (2004) occurred in the lower crust of the Indian shield and in the Pamir-Hindu Kush deep seismic zone (DSZ).

In this study, we further examine the depths of moderate earthquakes beneath the Himalayan-Tibetan region with the combination of the detailed velocity structures and the high signal-to-noise ratio of broadband seismograms. We complement the studies by Chen and Yang (2004) with an analysis of broadband global waveform data from the past ten years. We determine focal depths and fault slip directions by matching synthetic seismograms to $\mathrm{P}$ waveforms following the Kikuchi and Kanamori (1982) approach. Velocity structures from recent teleseismic imaging and seismic refraction surveys are taken into account. We find no evidence for moderate earthquakes outside the deep seismic zones that are located in the mantle.

\section{Data and methods}

Seismicity in the Himalayan-Tibetan region is widespread across distinct tectonic provinces. The
United States Geological Survey (USGS) Preliminary Determination of Epicenter (PDE) catalog includes $\sim 2500$ earthquakes of $M>5.0$ in and around the Tibetan plateau during the past fifty years (Figure 1). Three earthquakes had magnitudes of $M_{\mathrm{W}} \geq 8.0,22$ had magnitudes of $M_{\mathrm{W}} 7.0-7.9$, and 193 had magnitudes of $M_{\mathrm{W}} 6.0-6.9$. There are two zones with earthquakes deeper than $50 \mathrm{~km}$ : the Pamir-Hindu Kush and the Indo-Myanmar DSZs (Frohlich, 2006).

We analyze waveforms that are recorded at epicentral distances between $30^{\circ}$ and $95^{\circ}$ (Figure 2). The data are provided by the Incorporated Research Institutes for Seismology (IRIS) Data Management Center (DMC). Within the teleseismic distance range, $\mathrm{P}$ waves are not significantly influenced by strong velocity gradients in the crust and upper mantle. Focal depths are determined by analyzing the interference of the direct $\mathrm{P}$ wave with the surface reflections $\mathrm{pP}$ and $\mathrm{sP}$. We examine recordings of earthquakes with magnitudes between $M_{\mathrm{W}} 5.7$ and $M_{\mathrm{W}} 7.0$. These earthquakes have relatively simple source time functions but sufficiently high signalto-noise ratios at teleseismic stations. We examine 45 earthquakes that occurred between 2001 and 2010 with USGS PDE focal depths that range between 0 and $150 \mathrm{~km}$ (Table 1). In addition, we analyze the only earthquake outside of the Pamir-Hindu Kush and IndoMyanmar DSZs between 1990 and 2000 with a reported

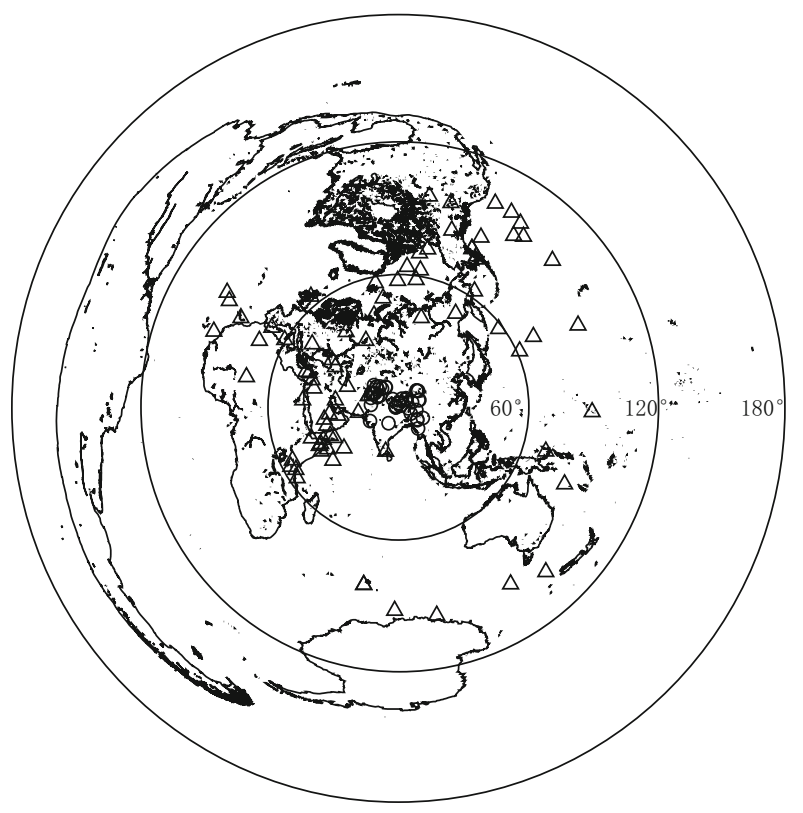

Figure 2 Global map showing the locations of seismic stations (open triangles) and earthquake epicenters (open circles) used in this study. 
Table 1 Source parameters of earthquakes obtained from teleseismic waveform inversion

\begin{tabular}{|c|c|c|c|c|c|c|c|c|c|c|c|}
\hline \multirow{2}{*}{ ID } & \multicolumn{2}{|c|}{ Origin time (GMT) } & \multirow{2}{*}{$\begin{array}{l}\lambda_{\mathrm{E}} \\
{ }^{\circ} \\
\end{array}$} & \multirow{2}{*}{$\begin{array}{c}\varphi_{\mathrm{N}} \\
{ }^{\circ}\end{array}$} & \multirow{2}{*}{$\begin{array}{c}H \\
/ \mathrm{km}\end{array}$} & \multirow{2}{*}{$M_{\mathrm{W}}$} & \multicolumn{3}{|c|}{ Fault plane } & \multirow{2}{*}{ Misfit } & \multirow{2}{*}{$\begin{array}{c}\text { Moho } \\
\text { depth/km }\end{array}$} \\
\hline & a-mo-d & $\mathrm{h}: \min$ & & & & & Strike ${ }^{\circ}$ & $\operatorname{Dip} /{ }^{\circ}$ & Rake/ ${ }^{\circ}$ & & \\
\hline 0 & $1997-05-21$ & $22: 51$ & 80.04 & 23.98 & 38 & 5.6 & 283 & 26 & 124 & 0.33 & 43 \\
\hline 1 & 2001-01-28 & 01:02 & 70.52 & 23.51 & 14 & 5.7 & 286 & 43 & 100 & 0.24 & 45 \\
\hline 2 & 2001-03-05 & $05: 50$ & 86.90 & 34.37 & 13 & 5.6 & 170 & 64 & -153 & 0.52 & 70 \\
\hline 3 & 2001-11-23 & $20: 43$ & 71.51 & 36.39 & 93 & 6.0 & 254 & 45 & 136 & 0.43 & 60 \\
\hline 4 & 2002-01-03 & 07:05 & 70.69 & 36.09 & 117 & 6.0 & 216 & 27 & 71 & 0.39 & 60 \\
\hline 5 & $2002-03-25$ & $14: 56$ & 69.32 & 36.06 & 5 & 5.9 & 16 & 39 & 98 & 0.38 & 60 \\
\hline 6 & 2002-04-12 & 04:00 & 69.42 & 35.96 & 5 & 5.7 & 204 & 46 & 96 & 0.46 & 60 \\
\hline 7 & $2002-07-13$ & $20: 06$ & 69.98 & 30.80 & 30 & 5.5 & 171 & 66 & 18 & 0.42 & 60 \\
\hline 8 & $2002-11-20$ & $21: 32$ & 74.51 & 35.41 & 6 & 6.0 & 204 & 30 & -91 & 0.54 & 60 \\
\hline 9 & $2003-02-24$ & 02:03 & 77.23 & 39.61 & 30 & 5.7 & 239 & 33 & 69 & 0.50 & 50 \\
\hline 10 & 2003-03-12 & 04:47 & 77.43 & 39.36 & 12 & 5.4 & 245 & 33 & 79 & 0.42 & 50 \\
\hline 11 & 2003-03-29 & $11: 46$ & 70.58 & 35.98 & 96 & 5.8 & 177 & 52 & 38 & 0.51 & 60 \\
\hline 12 & 2003-04-17 & 00:48 & 96.48 & 37.53 & 9 & 6.2 & 294 & 29 & 91 & 0.35 & 70 \\
\hline 13 & 2003-07-07 & $06: 55$ & 89.47 & 34.61 & 20 & 5.7 & 60 & 81 & 6 & 0.53 & 65 \\
\hline 14 & 2003-09-01 & $23: 16$ & 75.32 & 38.60 & 4 & 5.7 & 107 & 47 & -153 & 0.60 & 60 \\
\hline 15 & 2004-03-27 & $18: 47$ & 89.18 & 33.95 & 7 & 5.9 & 187 & 44 & -78 & 0.47 & 65 \\
\hline 16 & 2004-07-11 & 23:08 & 83.67 & 30.69 & 4 & 6.3 & 359 & 45 & -96 & 0.48 & 70 \\
\hline 17 & $2004-11-17$ & $20: 58$ & 71.86 & 39.19 & 6 & 5.8 & 185 & 88 & 11 & 0.65 & 60 \\
\hline 18 & 2005-02-25 & 23:04 & 72.71 & 38.11 & 111 & 5.6 & 343 & 45 & -47 & 0.51 & 60 \\
\hline 19 & 2005-04-07 & 20.04 & 83.66 & 30.49 & 6 & 6.3 & 170 & 43 & -67 & 0.25 & 70 \\
\hline 20 & 2005-06-01 & 20:06 & 94.63 & 28.88 & 22 & 5.6 & 209 & 6 & 28 & 0.34 & 58 \\
\hline 21 & 2005-09-18 & $07: 25$ & 94.78 & 24.56 & 83 & 5.6 & 271 & 54 & 50 & 0.67 & 45 \\
\hline 22 & 2005-10-08 & $10: 46$ & 73.10 & 34.73 & 8 & 6.1 & 328 & 39 & 77 & 0.46 & 60 \\
\hline 23 & 2005-10-08 & $12: 25$ & 73.12 & 34.77 & 3 & 5.9 & 96 & 47 & 39 & 0.85 & 60 \\
\hline 24 & 2005-10-09 & 08:30 & 73.18 & 34.67 & 6 & 5.7 & 344 & 37 & 122 & 0.27 & 60 \\
\hline 25 & 2006-07-06 & 03:57 & 71.82 & 39.13 & 5 & 5.8 & 285 & 59 & 145 & 0.52 & 60 \\
\hline 26 & 2007-01-08 & $17: 21$ & 70.31 & 39.80 & 9 & 6.1 & 187 & 65 & 16 & 0.40 & 60 \\
\hline 27 & 2007-05-05 & 08:51 & 81.97 & 34.25 & 4 & 6.1 & 220 & 88 & -36 & 0.64 & 70 \\
\hline 28 & 2008-01-09 & $08: 26$ & 85.17 & 32.29 & 8 & 6.3 & 206 & 46 & -78 & 0.19 & 70 \\
\hline 29 & 2008-01-16 & $11: 54$ & 85.16 & 32.33 & 6 & 5.8 & 23 & 44 & -102 & 0.46 & 70 \\
\hline 30 & 2008-08-21 & $12: 24$ & 97.68 & 25.04 & 9 & 5.9 & 7 & 80 & 173 & 0.40 & 45 \\
\hline 31 & 2008-08-25 & $13: 21$ & 83.52 & 30.90 & 19 & 6.3 & 30 & 48 & -93 & 0.59 & 70 \\
\hline 32 & 2008-09-25 & 01:47 & 83.47 & 30.83 & 19 & 5.6 & 208 & 75 & 12 & 0.81 & 70 \\
\hline 33 & 2008-10-05 & $15: 52$ & 73.82 & 39.53 & 4 & 6.4 & 246 & 38 & 102 & 0.35 & 60 \\
\hline 34 & 2008-10-05 & $22: 56$ & 69.47 & 33.89 & 31 & 5.8 & 218 & 80 & 10 & 0.40 & 60 \\
\hline 35 & 2008-10-06 & 08:30 & 90.35 & 29.81 & 4 & 6.3 & 44 & 48 & -75 & 0.30 & 75 \\
\hline 36 & 2008-11-10 & 01:22 & 95.83 & 37.56 & 20 & 6.0 & 252 & 28 & 63 & 0.58 & 70 \\
\hline 37 & 2009-07-24 & 03:11 & 85.86 & 31.12 & 26 & 5.4 & 318 & 74 & 170 & 0.67 & 70 \\
\hline 38 & 2009-08-28 & 01:52 & 95.68 & 37.72 & 11 & 6.1 & 295 & 31 & 95 & 0.27 & 70 \\
\hline 39 & 2009-09-03 & $19: 51$ & 94.71 & 24.32 & 98 & 5.8 & 144 & 46 & 142 & 0.56 & 45 \\
\hline 40 & 2009-09-21 & 08:53 & 91.42 & 27.35 & 13 & 6.0 & 281 & 6 & 99 & 0.52 & 60 \\
\hline 41 & 2009-09-21 & $19: 38$ & 94.80 & 20.40 & 88 & 5.5 & 227 & 33 & 4 & 0.77 & 45 \\
\hline 42 & $2010-02-27$ & $23: 21$ & 70.05 & 35.91 & 80 & 5.6 & 295 & 24 & 95 & 0.70 & 60 \\
\hline 43 & 2010-03-24 & 02:06 & 92.70 & 32.50 & 8 & 5.6 & 162 & 74 & -108 & 0.47 & 68 \\
\hline 44 & 2010-04-13 & $23: 49$ & 96.63 & 33.27 & 5 & 6.7 & 210 & 67 & -164 & 0.35 & 76 \\
\hline 45 & 2010-05-29 & $02: 30$ & 96.25 & 33.25 & 26 & 5.6 & 75 & 88 & 11 & 0.69 & 76 \\
\hline
\end{tabular}

Note: ID is the number of earthquake in origin time order. $\lambda_{\mathrm{E}}$ and $\varphi_{\mathrm{N}}$ are longitude and latitude of earthquakes taken from the USGS PDE catalog. $H$ is the depth below free surface. Strike and dip of fault plane are taken from the Harvard CMT catalog. Misfit is least-squares variance between observed and synthetic seismograms. Moho depths are obtained from previous studies (Yuan et al., 1997; Mejia, 2001; Kind et al., 2002; Wittlinger et al., 2004; Mitra et al., 2005; Zhao et al., 2010) and used for waveform modeling. 
depth deeper than $35 \mathrm{~km}$. This event (event 0 in Table 1) occurred beneath the Indian shield.

The teleseismic inversion method developed by Kikuchi and Kanamori (1982) is used to model waveforms. We ignore spatial finiteness and parameterize the moment rate functions with four 2-s to 3 -s wide overlapping triangles. The strike and dip of the fault plane are obtained from the global centroid moment tensor (CMT) catalog. In our analysis we determine the fault rake, the moment rate function and event depth. According to the USGS PDE depth, we analyze the P waveform in a $30-70 \mathrm{~s}$ long window that begins $5 \mathrm{~s}$ be- fore the $\mathrm{P}$ wave onset. We calculate synthetic $\mathrm{P}$ waveforms using a velocity model comprised of a uniform mantle $\left(v_{\mathrm{P}}=8.10 \mathrm{~km} \cdot \mathrm{s}^{-1}, v_{\mathrm{S}}=4.68 \mathrm{~km} \cdot \mathrm{s}^{-1}\right)$ and crust $\left(v_{\mathrm{P}}=6.50 \mathrm{~km} \cdot \mathrm{s}^{-1}, v_{\mathrm{S}}=3.74 \mathrm{~km} \cdot \mathrm{s}^{-1}\right)$ for the source structure (Table 2; Kennett et al., 1995; Griffin et al., 2011). We vary the depth of the Moho (Table 1) for the various regions using constraints obtained from simultaneous inversion of surface wave dispersion and receiver functions (Yuan et al., 1997; Mejia, 2001; Kind et al., 2002; Wittlinger et al., 2004; Mitra et al., 2005; Zhao et al., 2010) and from refraction surveys (Murty et al., 1998).

Table 2 Source and receiver structures used to compute Green's functions

\begin{tabular}{|c|c|c|c|c|}
\hline & $v_{\mathrm{S}} /\left(\mathrm{km} \cdot \mathrm{s}^{-1}\right)$ & $v_{\mathrm{P}} /\left(\mathrm{km} \cdot \mathrm{s}^{-1}\right)$ & Density $/\left(\mathrm{kg} \cdot \mathrm{m}^{-3}\right)$ & Thickness/km \\
\hline \multirow[t]{2}{*}{ Source structure } & 6.50 & 3.74 & 2.87 & Varying thickness \\
\hline & 8.10 & 4.68 & 3.30 & \\
\hline \multirow[t]{3}{*}{ Receiver structure } & 5.57 & 3.36 & 2.65 & 15.0 \\
\hline & 6.50 & 3.74 & 2.87 & 18.0 \\
\hline & 8.10 & 4.68 & 3.30 & \\
\hline
\end{tabular}

The Kikuchi and Kanamori (1982) approach is designed to analyze teleseismic waveform data. The method relies on measuring the travel time differences between the direct $\mathrm{P}$ wave and the surface reflections $\mathrm{pP}$ and $\mathrm{sP}$ from the surface directly above the earthquake (Engdahl et al., 1998; Bai et al., 2006, 2007). The surface reflections are recorded after the direct $\mathrm{P}$ phase with a time delay that changes slowly with distance but rapidly with depth. Therefore, they provide powerful constrains on focal depth. As $\mathrm{pP}$ and $\mathrm{sP}$ are not isolated signals for shallow earthquakes, the arrival times are determined by modeling the waveform $\mathrm{P}, \mathrm{pP}$, and $\mathrm{sP}$ interference. We assume that the earthquakes have a point source within a $\pm 1 \mathrm{~km}$ area in order to obtain the focal depth in more details.

The accuracy of the earthquake depth estimates is controlled by several factors, including the knowledge of the crustal structure, available phases, and arrival-time reading accuracy. The elements of the algorithm that contribute to the improvements of the depth accuracy include: (1) use of both the arrival times and amplitudes of the surface reflections in addition to the direct $P$ phase, (2) use of an improved 1D velocity model for the source side with varying crustal thickness, and (3) selection criteria for events with a sufficient number of quality seismograms.

Figure 3 shows comparison between observed and synthetic waveforms at the preferred depth and at the
USGS PDE depth for the event 19 and event 42. The shape of the synthetic waves varies with focal depth due to the change of the arrival times of the surface reflections. Event 19 is shallow so that the depth phases are recorded only 2-3 s after the direct $\mathrm{P}$ waves. Both timing and amplitude of the observed waveforms are consistent with the synthetic waves at a depth of $6 \mathrm{~km}$. In contrast, event 42 is deep and the surface reflections are clearly separated from the $\mathrm{P}$ wave. The time intervals between pP-P and sP-P are about $20 \mathrm{~s}$ and $30 \mathrm{~s}$, respectively. The preferred focal depth is about $80 \mathrm{~km}$; $25 \mathrm{~km}$ shallower than the USGS PDE depth.

The typical values of crustal $v_{\mathrm{P}}$ and $v_{\mathrm{S}}$ range between 6.2 to $6.6 \mathrm{~km} \cdot \mathrm{s}^{-1}$ and 3.5 to $3.9 \mathrm{~km} \cdot \mathrm{s}^{-1}$ (Kennett et al., 1995; Yuan et al., 1997; Mejia et al., 2001). A 5\% lower velocity and $5 \mathrm{~km}$ thicker crust lead to a decrease in estimated focal depths up to $1 \mathrm{~km}$ and $3 \mathrm{~km}$ for shallow and deep earthquakes, respectively. There are some additional errors in arrival time readings of depth phases and global CMT solution for shallow earthquakes. We infer that the uncertainties in focal depth determinations are predominately within $\pm 3 \mathrm{~km}$.

\section{Results}

The source parameters of earthquakes determined from waveform modeling are listed in Table 1 and shown in Figures 4 and 5. Figure 4a compares the focal depths 
Event 19 (2005-04-07 20:04)

$\operatorname{ALE}\left(\Delta 66.0^{\circ}, \operatorname{Az} 355.4^{\circ}\right) \quad \operatorname{MBAR}\left(\triangle 59.0^{\circ}, \operatorname{Az} 248.7^{\circ}\right)$
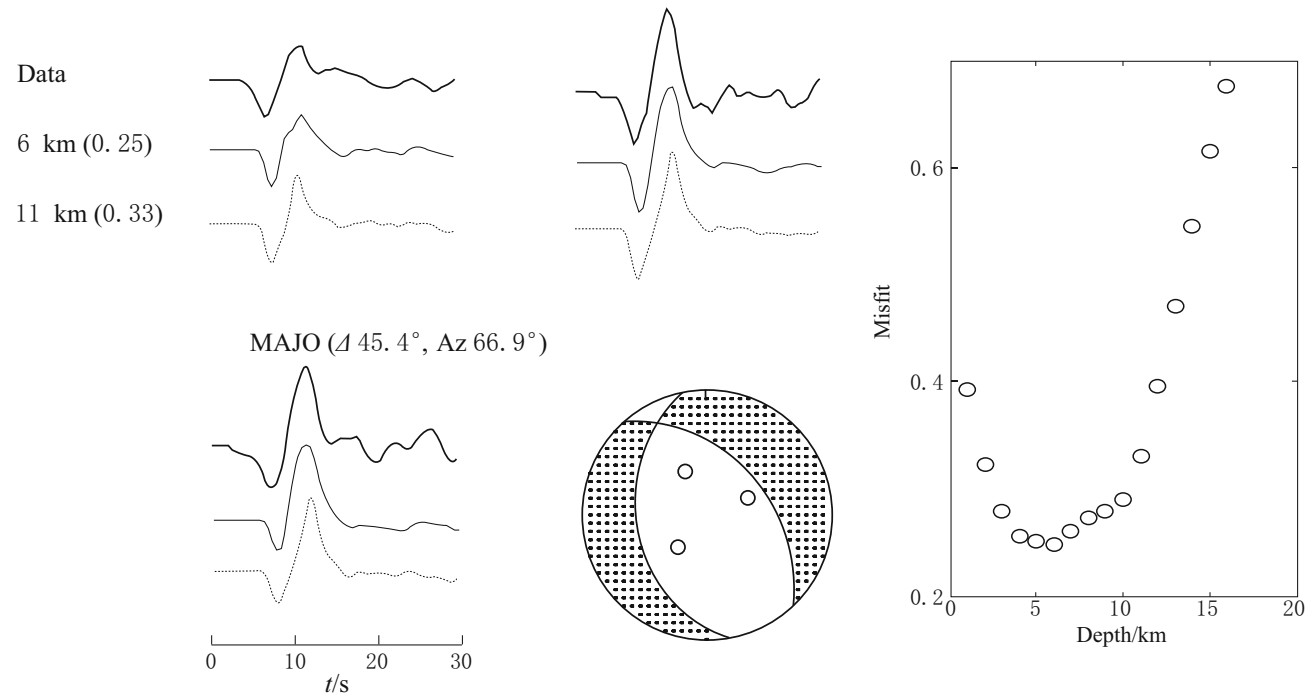

Event $42(2010-02-27 \quad 23: 21)$

$$
\operatorname{HIA}\left(\Delta 38.3^{\circ}, \mathrm{Az} 53.5^{\circ}\right)
$$

Data

$80 \mathrm{~km}(0.70)$

$105 \mathrm{~km}(0.96)$

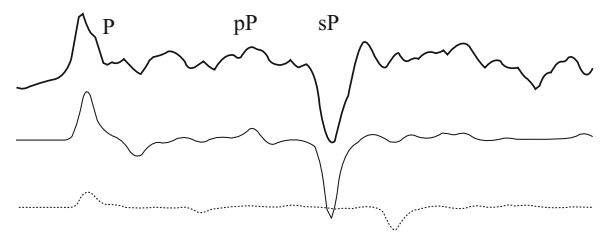

$\operatorname{KBS}\left(\Delta 49.0^{\circ}, \mathrm{Az} 347.5^{\circ}\right)$

Data

$80 \mathrm{~km}(0.70)$

$105 \mathrm{~km}(0.96)$
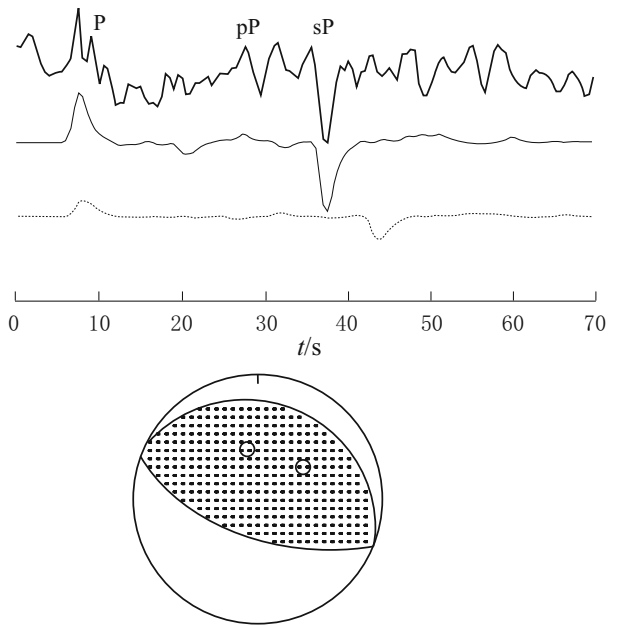

$\mathrm{KKM}\left(\Delta 51.7^{\circ}, \mathrm{Az} 113.8^{\circ}\right)$
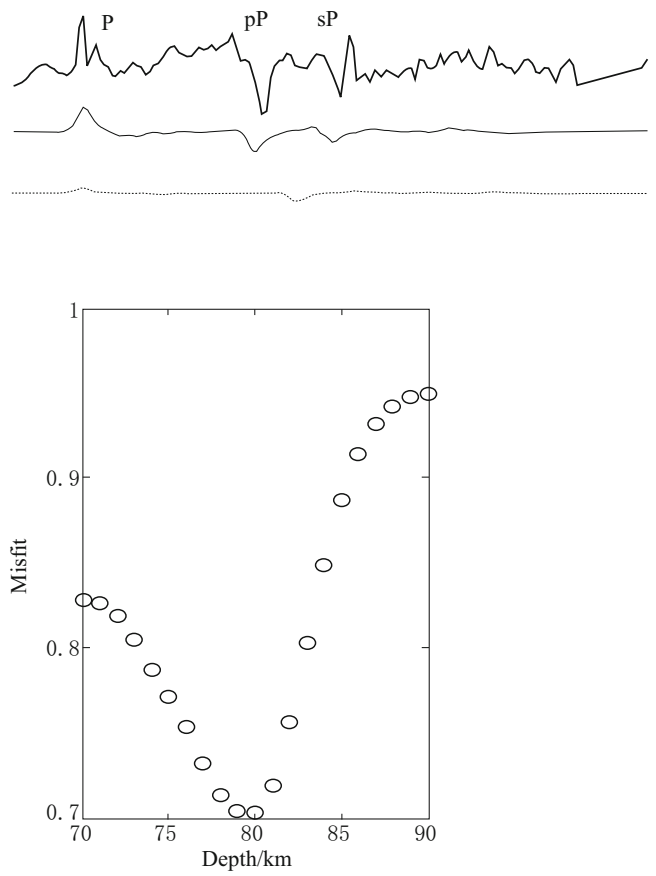

Figure 3 P waveform modelings for event 19 (upper) and event 42 (lower). Shown are the raw data (thick lines), the synthetics at the preferred depth (thin lines), and the synthetics at the depth listed in the USGS PDE catalog (dotted lines). The numbers in parentheses following the depth are least-squares misfit between observed and synthetic seismograms. Waveforms are zero-pass-filtered from 0.01 to $1 \mathrm{~Hz}$. The sensitivity of the least-squares misfits to the change of depth is shown by the misfits versus depth plots.

determined in this study and those listed in the USGS PDE catalog and the global CMT. On average, the depths of the 46 earthquakes differ about $8 \mathrm{~km}$ with a maximum difference of $27 \mathrm{~km}$ (event 8) with respect to the USGS PDE, and about $9 \mathrm{~km}$ with a maximum difference of $35 \mathrm{~km}$ (event 42 ) with respect to the global CMT. 

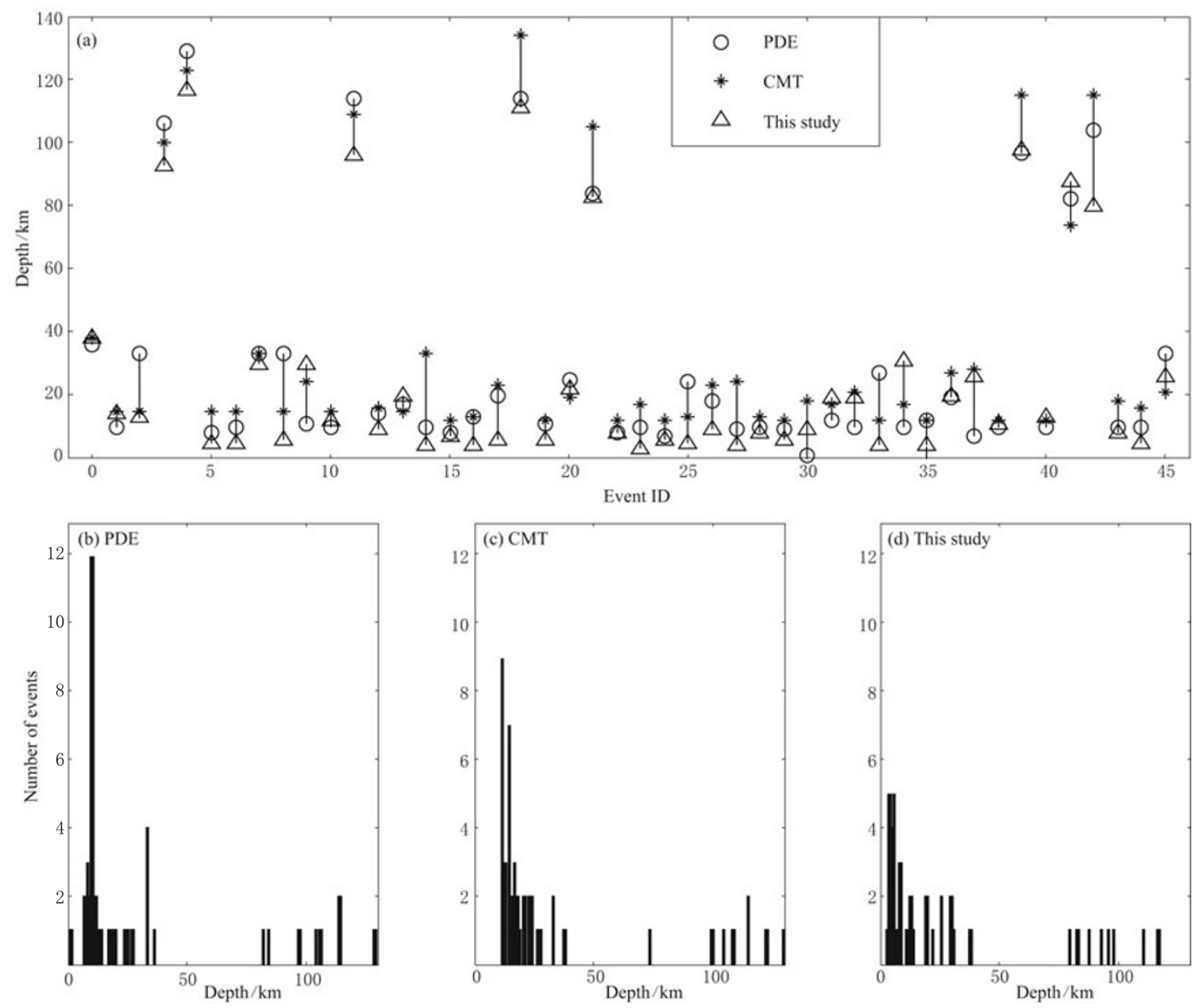

Figure 4 (a) The comparison of earthquake depths between those listed in the USGS PDE catalog, global CMT catalog, and those obtained in this study. The earthquakes are plotted in the origin time order. Histograms of earthquake depths from the USGS PDE catalog (b), global CMT catalog (c), and from this study $(d)$.

Event $0\left(80.04^{\circ} \mathrm{E}, 23.98^{\circ} \mathrm{N}\right.$ in Figure 5) occurred near the Moho beneath the Indian shield. This event had a moment magnitude of $M_{\mathrm{W}} 5.6$ at a depth of 38 $\mathrm{km}$, which is close to the depth $(35 \mathrm{~km})$ estimated by Jackson (2002) and Sloan et al. (2011). In this event the $\mathrm{sP}$ phase is clearly separated from the direct $\mathrm{P}$ by about $15 \mathrm{~s}$. A refraction survey across the source region (Murty et al., 1998) indicates that the Moho is at a depth of $43 \mathrm{~km}$, which indicates that event 0 originated in the lower crust of the Indian shield. The NE-SW trending faults in the source region of this event are consistent with the strike of one of the double-couple nodal planes. Along the Himalayan foreland, the effective elastic thickness, as estimated from gravity measurements (Jordan and Watts, 2005; Audet and Bürgmann, 2011), is significantly larger $(30-70 \mathrm{~km})$ than the central part of the plateau $(0-20 \mathrm{~km})$. This observation may explain the great depths of some earthquakes beneath the Himalayan foreland.
Among the 45 earthquakes that occurred between 2001 and 2010, 37 are at depths less than $35 \mathrm{~km}$ (Figure 4a). For seven of these shallow earthquakes, the focal depths have been reported previously by using similar long-period body wave inversion method (Sloan et al., 2011). Our results are in good agreement with Sloan et al. (2011) for most of the earthquakes. However, we estimate that event 31 is at a depth of $21 \mathrm{~km}$, whereas Sloan et al. (2011) estimate a depth $8 \mathrm{~km}$ for event 31. In the USGS and global CMT catalogs, there is a peak at earthquake depths of $10 \mathrm{~km}$ (Figures $4 \mathrm{~b}$ and $4 \mathrm{c}$ ). Notably, this peak corresponds to the default depth of shallow earthquakes with unconstrained depths (http://www.usgs.gov). On the basis of our waveform modeling approach, we determine that most earthquakes are located at depths of $3-15 \mathrm{~km}$, with the peak occurring at a depth of $5 \mathrm{~km}$ (Figure 4d). There is no systematic increase in focal depths related to the collision of the Indian plate with Asia. 


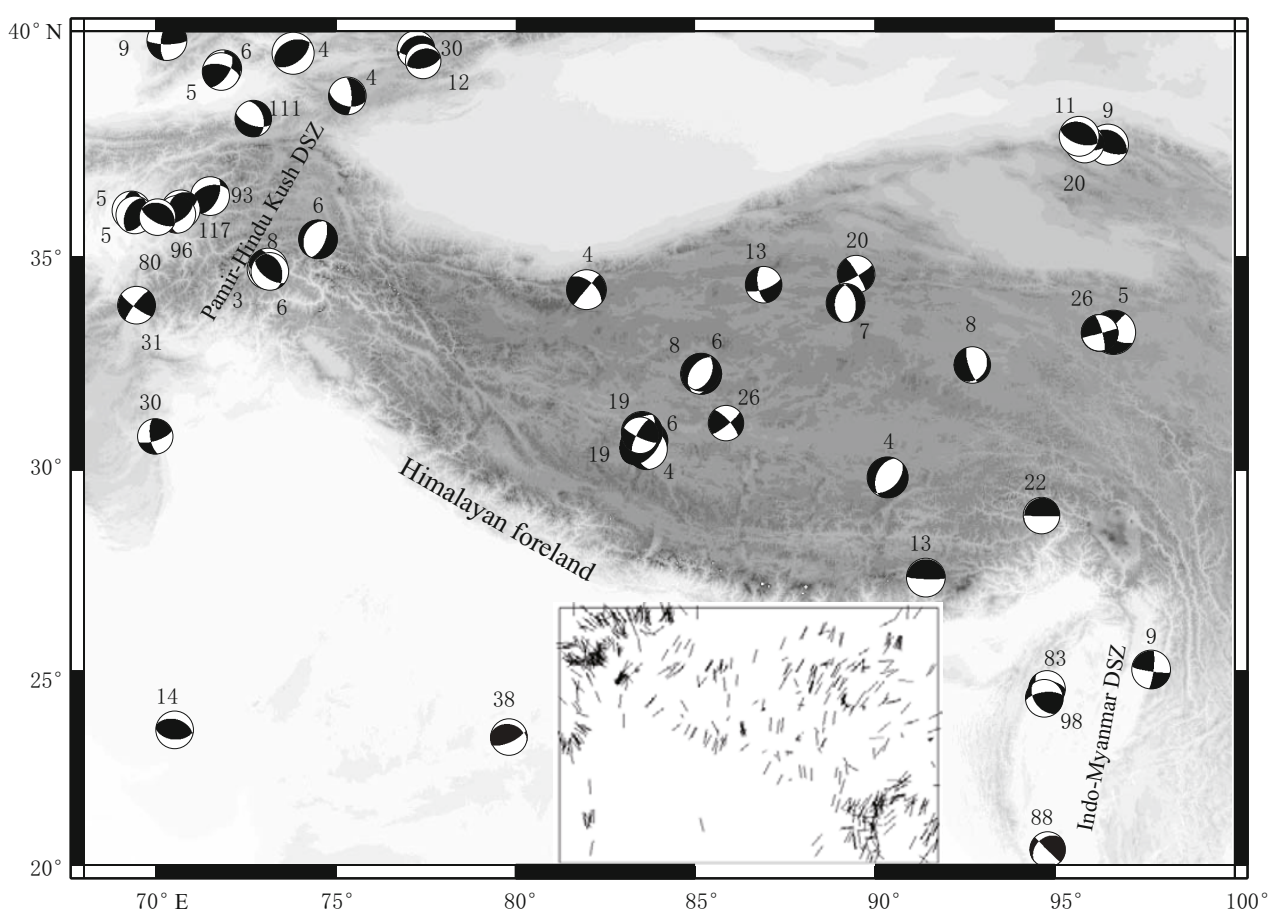

Figure 5 Earthquake focal mechanisms determined from waveform modeling. The numbers next to the beach balls are centroid depth (in $\mathrm{km}$ ). The insert shows compressional axes of earthquakes of $M>5.0$ occurred in the past fifty years.

Eight earthquakes have focal depths between 80 and $120 \mathrm{~km}$. All of these earthquakes are within the Pamir-Hindo Kush or the Indo-Myanmar DSZs (Figure $5)$. Although there is a clear separation of focal depth with seismic events being concentrated between 0 and $40 \mathrm{~km}$ and between 80 and $120 \mathrm{~km}$, these earthquakes show no depth correlation with the bimodal distribution of seismicity as described in the jelly sandwich model.

The global CMT solutions of earthquakes in the past forty years reveal predominantly NNW-SSE compression (see the inset in Figure 5), which is consistent with the direction of continental collision. The earthquakes exhibit different types of focal mechanisms (Figure 5). Thrust faulting earthquakes mainly occurred along the northern Tibetan plateau and the Himalayan foreland, due to ongoing shortening associated with folds and thrust belts in the north and continental collision in the south. In contrast, normal and left-lateral strike-slip faulting earthquakes were mostly concentrated over central Tibet, where the topography reaches maximum values.

\section{Discussion and conclusions}

Over the past thirty years, a number of active and passive seismic experiments have been carried out to study the velocity structure of the Himalayan-Tibetan region (Yuan et al., 1997; Mejia, 2001; Kind et al., 2002; Wittlinger et al., 2004; Zhao et al., 2010). However, the crust and mantle beneath the Indian shield, a type example of continental mantle seismicity, has only recently been imaged in moderate detail through seismic experiments (Mitra et al., 2005; Schulte-Pelkum et al., 2005; Rai et al., 2006). These studies illuminate significant features of the Tibetan Moho: (1) the Moho is extremely deep (up to $85 \mathrm{~km}$ ) beneath western Tibet, (2) the Moho depth varies by as much as $40 \mathrm{~km}$, and (3) the Moho exhibits the major offsets across large-scale surface faults, such as Himalayan thrust belt.

In disagreement with Chen and Yang (2004), we find none of the earthquakes beneath Himalayan foreland to be located within the mantle. The focal depths of earthquakes beneath Himalayan foreland range between $0-40 \mathrm{~km}$ and their hypocenters are shallower than published corresponding Moho depths. All earthquakes deeper than $80 \mathrm{~km}$ are clearly associated with the Pamir-Hindu Kush and Indo-Myanmar DSZs, which contains anomalously deep seismicity due to the convergence of micro plates (Frohlich, 2006). In agreement with Priestley et al. (2008), we find evidence for seismicity in the lower crust. One earthquake (event 0) oc- 
curred $\sim 5 \mathrm{~km}$ above the Moho of the Indian shield, where the effective elastic thickness is high. This observation supports the ideas that the lower crust is strong with respect to the uppermost mantle and that the strength of the continental lithosphere is governed by the crustal seismic layer.

As expected, the global CMT solutions show dominant NNW-SSE trending compressions, supporting the idea that continental collision is still ongoing. Shallow thrust faulting earthquakes in the northern margin area exhibit nearly NS shortening in association with the fold and thrust belts. Normal and left-lateral strike-slip faulting mainly occurs in central Tibet, where the topography reaches maximum values.

Acknowledgements We thank the IRIS/DMC for providing the global network waveform data and J. Naliboff for useful discussions. The Generic Mapping Tools of Wessel and Smith (1995) were used to prepare the figures. This research was funded by the grants of 100-talent program of Chinese Academy of Sciences to L. Bai, the US National Science Foundation (EAR0944167) to J. Ritsema, and the National Natural Science Foundation of China (40930317) to J. Zhao.

\section{References}

Audet P and Bürgmann R (2011). Dominant role of tectonic inheritance in supercontinent cycles. Nature Geosci 4, doi:10.1038/NGEO1080.

Bai L, Kawasaki I, Zhang T and Ishikawa Y (2006). An improved double-difference earthquake location algorithm using SP phases: application to the foreshock and aftershock sequences of the 2004 earthquake offshore of the Kii peninsula, Japan $\left(M_{\mathrm{W}} 7.5\right)$. Earth Planets Space 58: 823-830.

Bai L, Bergman E A, Engdahl E R and Kawasaki I (2007). The 2004 earthquake offshore of the Kii peninsula, Japan: Hypocentral relocation, source mechanism and tectonic implications. Phys Earth Planet Int 165: 47-55.

Bürgmann R and Dresen G (2008). Rheology of the lower crust and upper mantle: evidence from rock mechanics, geodesy, and field observations. Annu Rev Earth Planet Sci 36: 531-567.

Brace W F and Kohlstedt D L (1980). Limits on lithospheric stress imposed by laboratory experiments. J Geophys Res 85: $6248-6252$.

Burov E B and Watts A B (2006). The long-term strength of continental lithosphere: "jelly sandwich" or "crème brûlèe"? GSA Today 16(1): 4-10.

Chen W-P and Molnar P (1983). Focal depths of intracontinental and intraplate earthquakes and their implications for the thermal and mechanical properties of the litho- sphere. J Geophys Res 88: 4 183-4 214.

Chen W-P and Tseng T-L (2007). Small 660-km seismic discontinuity beneath Tibet implies resting ground for detached lithosphere. J Geophys Res 112: B05309, doi:10.1029/2006JB004607.

Chen W-P and Yang Z (2004). Earthquakes beneath the Himalaya and Tibet: Evidence for a strong lithospheric mantle. Science 304: 1 949-1 952.

Cloos M (1993). Lithospheric buoyancy and collisional orogenesis: Subduction of oceanic plateaus, continental margins, island arcs, spreading ridges and seamounts. Geol Soc Am Bull 105: 715-737.

Deng Q, Zhang P, Ran Y, Yang X, Min W and Chu Q (2003). Basic characteristics of active tectonics of China. Sci China (Series D) 46(4): 356-372.

Engdahl E R, Hilst R and Buland R (1998). Global teleseismic earthquake relocation with improved travel times and procedures for depth determination. Bull Seismol Soc Am 88: 722-743.

Frohlich (2006). Deep Earthquakes. Cambridge Univ. Press, Cambridge, 574pp.

Griffin J D, Nowack R L, Chen W-P and Tseng T-L (2011). Velocity structure of the Tibetan lithosphere: Constraints from P-wave travel times of regional earthquakes. Bull Seismol Soc Am 101: 1 938-1 947, doi: $10.1785 / 0120100229$.

Jackson J (2002). Strength of the continental lithosphere: time to abandon the jelly sandwich? GSA Today 12: 410.

Jodan T A and Watts A B (2005). Gravity anomalies, flexure and the elastic thickness structure of the India-Eurasia collisional system. Earth Planet Sci Lett 236: 732-750.

Jiang M, Zhou S, Tong X, Liang X and Chen Y (2009). Accurate depth determination of deep earthquake in southern Tibet and its geodynamic implication. Chinese $J$ Geophys 52: 2 237-2 244, doi:10.3969/j.issn.0001.5733. 2009.09.00 (in Chinese).

Kapp P, Yin A, Harrison T M and Ding L (2005). Cretaceous-Tertiary shortening, basin development and volcanism in central Tibet. Geol Soc Am Bull 117: 865878, doi:10.1130/B25595.1.

Kennett B L N, Engdahl E R and Buland R (1995). Constraints on seismic velocities in the Earth from traveltimes. Geophys J Int 122: 403-416.

Kikuchi M and Kanamori H (1982). Inversion of complex body waves. Bull Seismol Soc Am 72: 491-506.

Kind R, Yuan X, Saul J, Nelson D, Sobolev S V, Mechie J, Zhao W, Kosarev G, Ni J, Achauer U and Jiang M (2002). Seismic images of crust and upper mantle beneath Tibet: Evidence for Eurasian plate subduction. Science 298: 1 219-1 221.

Kohlstedt D L, Evans B and Mackwell S J (1995). Strength of the lithosphere: Constraints imposed by laboratory experiments. J Geophys Res 100(B9): 17 587-17 602, 
doi:10.1029/95JB01460.

Lee C-T A, Luffi P and Chin E J (2011). Building and destroying continental mantle. Annu Rev Earth Planet Sci 39: 59-90.

Lowry A R and Smith R B (1995). Strength and rheology of the western U.S. Cordillera. J Geophys Res 100(B9): 17 947-17 963, doi:10.1029/95JB00747.

Liang X, Zhou S, Chen Y, Jin G, Xiao L, Liu P, Fu Y, Tang Y, Lou X and Ning J (2008). Earthquake distribution in southern Tibet and its tectonic implications. J Geophys Res 113: B12409, doi:10.1029/2007JB005101.

Maggi A, Jackson J, McKenzie D and Priestley K (2000a). Earthquake focal depths, effective elastic thickness, and the strength of the continental lithosphere. Geology 28: 495-498.

Maggi A, Jackson J, Priestley K and Baker C (2000b). A reassessment of focal depth distribution in southern Iran, the Tien Shan and northern India: do earthquakes really occur in the continental mantle? Geophys J Int 143: 629-661.

McKenzie D, Jackson J and Priestley K (2005). Thermal structure of oceanic and continental lithosphere. Earth Planet Sci Lett 233: 337-349.

Mejia J A (2001). Lithospheric Structure Beneath the Tibetan Plateau Using Simultaneous Inversion of Surface Wave Dispersion and Receiver Functions. [Ph.D. Dissertation]. Saint Louis University, 333pp.

Mitra S, Priestley K, Bhattacharyya A and Gaur V K (2005). Crustal structure and earthquake focal depths beneath northeastern India and southern Tibet. Geophys J Int 160: 227-248.

Monsalve G, Sheehan A, Schuttle-Pelkum V, Rajaure S, Pandey M R and Wu F (2006). Seismicity and onedimensional velocity structure of the Himalayan collision zone: earthquakes in the crust and upper mantle. $J$ Geophys Res 111: B10301, doi:10.1029/2005JB004062.

Murty A S N, Mall D M, Murty P R K and Reddy P R (1998). Two-dimensional crustal velocity structure along Hirapur-Mandla profile from seismic refraction and wideangle reflection data. Pure Appl Geophys 152: 247-266.

Ozacar A A and Zandt G (2004). Crustal seismic anisotropy in central Tibet: implications for deformational style and flow in the crust. Geophys Res Lett 31: L23601, doi:10.1029/2004GL021096.

Priestley K, Jackson J and McKenzie D (2008). Lithospheric structure and deep earthquakes beneath India, the Himalaya and southern Tibet. Geophys J Int 172: 345-362, doi:10.1111/j.1365-246X.2007.03636.x.

Rai S, Priestley K, Gaur V, Mitra S, Singh M and Searle
M (2006). Configuration of the Indian Moho beneath the NW Himalaya and Ladakh. Geophys Res Lett 33: doi:10.1029/2006GL026076.

Royden L H, Burchfiel B C, King R W, Wang E, Chen Z L, Shen F and Liu Y P (1997). Surface deformation and lower crustal flow in Eastern Tibet. Science 276: 788790 .

Schulte-Pelkum V, Monsalve G, Sheehan A, Pandey M, Sapkota S, Bilham R and Wu F (2005). Imaging the Indian subcontinent beneath the Himalaya. Nature 435: 1222 1 225, doi:10.1038/nature03678.

Sloan R A, Jackson J A, McKenzie A and Priestley K (2011). Earthquake depth distributions in central Asia, and their relations with lithosphere thickness, shortening and extension. Geophys J Int 185: 1-29.

Tapponnier P, Xu Z, Roger F, Meyer B, Arnaud N, Wittlinger $G$ and Yang J (2001). Oblique stepwise rise and growth of the Tibet Plateau. Science 294: 1 671-1 677.

Thatcher W and Pollitz F F (2008). Temporal evolution of continental lithospheric strength in actively deforming regions. GSA Today 18: 4-11.

Wang Q, Zhang P, Freymueller J T, Bilham R, Larson K M, Lai X, You X, Niu Z, Wu J, Li Y, Liu J, Yang Z and Chen Q (2001). Present-day deformation in China constrained by global positioning system measurements. Science 294: 574-577.

Wessel P and Smith W H F (1995). New version of the Generic Mapping Tools released. EOS Trans AGU 76: 329.

Wittlinger G, Vergne J, Tapponnier P, Farra V, Poupinet G, Jiang M, Su H, Herquel G and Paul A (2004). Teleseismic imaging of subducting lithosphere and Moho offsets beneath western Tibet. Earth Planet Sci Lett 221: 117130.

Yin A and Harrison T N (2000). Geologic evolution of the Himalayan-Tibetan orogen. Annu Rev Earth Planet Sci 28: 211-280.

Yuan X, Ni J, Kind R, Mechie J and Sandvol E (1997). Lithospheric and upper mantle structure of southern Tibet from a seismological passive source experiment. $J$ Geophys Res 102: 27 491-27 500.

Zhao J, Yuan X, Liu H, Kumar P, Pei S, Kind R, Zhang Z, Teng J, Ding L, Gao X, Xu Q and Wang W (2010). The boundary between the Indian and Asian tectonic plates below Tibet. PNAS doi:10.1073/pnas.1001921107.

Zhu L and Helmberger D V (1996). Intermediate depth earthquakes beneath the India-Tibet collision zone. Geophys Res Lett 23: 435-438, doi:10.1029/96GL00385. 